\title{
Cellular Behavior in the Anteroposterior Axis of the Regenerating Forelimb of the Axolotl, Ambystoma mexicanum
}

\author{
Patrick W. Tank, ${ }^{1}$ Thomas G. Connelly, ${ }^{*}$ and Fred L. Bookstein $\dagger$ \\ Department of Anatomy--510, University of Arkansas for Medical Sciences, 4301 West Markham, Little Rock, Arkansas 72205; and \\ ${ }^{*}$ Department of Anatomy and Cell Biology and $\dagger$ Center for Human Growth and Development, \\ University of Michigan, Ann Arbor, Michigan 48109
}

Received September 12, 1984; accepted November 12, 1984

\begin{abstract}
Cellular behavior along the anteroposterior axis of the regenerating axolotl forelimb was studied by use of triploid $(3 N)$ tissue grafted into diploid $(2 N)$ hosts and three-dimensional computer reconstructions. Asymmetrical upper forelimbs were surgically constructed with one half (anterior or posterior) $3 N$ and the other half $2 N$. Limbs were amputated immediately after grafting or were permitted to heal for 5 or 30 days prior to amputation. When regenerates had attained the stage of digital outgrowth, the limbs were harvested and sectioned in the transverse axis for histological analysis. When all limbs bearing anterior grafts were considered as a group, $77 \%$ of the $3 \mathrm{~N}$ mesodermal cells were observed in the anterior side of the regenerates and $23 \%$ were located in the posterior side of the regenerates. When all limbs bearing posterior grafts were considered as a group, $76 \%$ of the $3 \mathrm{~N}$ mesodermal cells were found in the posterior side of the regenerate and $24 \%$ had crossed into the anterior side. Healing times of 0,5 , or 30 days prior to amputation had no effect on the experimental outeome. Three-dimensional computer reconstructions revealed that most $3 N$ cells of mesodermal origin underwent short-distance migration from anterior to posterior or from posterior to anterior and intermixed with diploid mesodermal cells near the midpoint of the regenerated anteroposterior axis. Some $3 N$ cells were observed at greater distances from the graft-host interface. By contrast, labeled epidermal cells from both anterior and posterior grafts exhibited long-distance migration across all surfaces of regenerated limbs. Details of a computer-assisted reconstruetive method for studying the threcdimensional distribution of labeled cells in tissues are presented. (c) 1985 Academic Press, Ine.
\end{abstract}

\section{INTRODUCTION}

The process of pattern formation during urodele limb regeneration is dependent upon highly organized cellular interactions (Bryant et al., 1981; French et al., 1976; Maden, 1977; Slack, 1980a; Stocum, 1978, 1980a; reviewed by Tank and Holder, 1981). Recently, triploid cell markers have been used to directly observe the consequences of these interactions (Muneoka and Bryant, 1984a,b; Muneoka et al., 1984; Pescitelli and Stocum, 1980; Rollman-Dinsmore and Bryant, 1984; Stocum, 1975; Thoms and Fallon, 1980). The cells of triploid animals display threc nucleoli in their nuclei and this marker is heritable. The marker does not suffer the drawback of dilution of label often associated with long-term studies utilizing tritiated thymidinelabeled cells. This makes it feasible to design longterm experiments aimed at exploring cellular behavior during pattern formation by using triploid markers in regenerating systems.

Several studies on pattern formation in the axolotl forelimb indicate that important cellular interactions occur in the region between digits 2 and 3 . First, when developing limb buds are rotated $180^{\circ}$, supernumerary

\footnotetext{
${ }^{1}$ To whom correspondence should be sent.
}

hands develop in the graft-host junction. Some of these supernumerary hands contain two digits that flex ventrad and two digits that flex dorsad (Thoms and Fallon, 1980). Second, when regeneration blastemas are rotated by $180^{\circ}$, some of the supernumerary limbs display mixed handedness like that observed by Thoms and Fallon (1980). The axis of this change in flexion of digits falls between digits 2 and 3 in $95 \%$ of the mixed supernumerary limbs (Tank, 1981). Finally, when triploid regeneration blastemas are grafted to diploid stumps with the A-P axis reversed, supernumerary limbs that contain approximately equal amounts of triploid and diploid tissue are formed in the grafthost junction (Muneoka and Bryant, 1984a). The boundary between the two tissue types falls between digits 2 and 3 in most of these supernumerary limbs.

The nature of the interactions that occur between cells arising from the anterior and posterior sides of the limb stump has not been clearly established. Through studies on surgically constructed symmetrical limbs it has been hypothesized that short-range cellular interactions occur between cells derived from the two sides of the limb stump (Bryant and Baca, 1978). Interpretation of these results has been confounded by the fact that the length of the time the graft is 
permitted to heal prior to amputation profoundly alters the result. Symmetrical regenerates may form on symmetrical stumps when amputation is performed immediately after grafting or no regeneration may occur if symmetrical limbs are completely healed (30 days) at time of amputation (Tank and Holder, 1978; Holder et al. 1980). This healing effect is thought to be caused by increased or decreased cellular contact across the plane of the surgical incision (Holder et al., 1980; Bryant et al., 1981). Amputation immediately after grafting may result in restricted short-range cellular interactions across the plane of the incision. After healing is completed ( 30 days), interactions may occur freely between cells from graft and host across the surgical incision, causing a result different from that seen in unhealed stumps (Holder et al., 1980).

The purpose of the present study is to observe the interaction of cells along the anteroposterior axis of the asymmetrical limb blastema following amputation at different times after grafting. These experiments are aimed at answering two questions: (1) Do cells freely cross from anterior to posterior or from posterior to anterior during regeneration of asymmetrical limb stumps? (2) What is the effect of variable healing time on cellular behavior in the anteroposterior axis of the regenerating limb? Triploid cells are utilized as markers in this study. Relating the final location of marked cells to the three-dimensional architecture of the regenerated limb has been accomplished by use of computer reconstruction techniques.

\section{MATERIALS AND METHODS}

Larval axolotls (Ambystoma mexicanum) were used in this study. All animals were siblings. One half of each spawning had been made triploid $(3 N)$ by the pressure induction method of Dasgupta (1962) and the untreated animals remained diploid $(2 N)$.

Animals of the 5-day healing group were kindly donated by the Developmental Biology Center, University of California, Irvine. They arrived at the University of Arkansas as embryos and were reared by the techniques described by Tank $(1982,1983)$. When larvae had attained a minimum length of $80 \mathrm{~mm}$ (range 80 $102 \mathrm{~mm}$ ) they were paired by size with one member of each pair carrying the $3 N$ cell marker. Animals were anesthetized in an aqueous solution of 1:1000 ethyl $\mathrm{m}$ aminobenzoate methanesulfonate (Eastman) and were arranged so that surgery could be performed on the right forelimbs of both animals. The anterior (flexor) half of the right $2 N$ upper forelimb was replaced by the anterior half of the right $3 N$ upper forelimb (Fig. 1). Skin, muscle, and connective tissues were grafted in this operation and care was taken to leave nerves

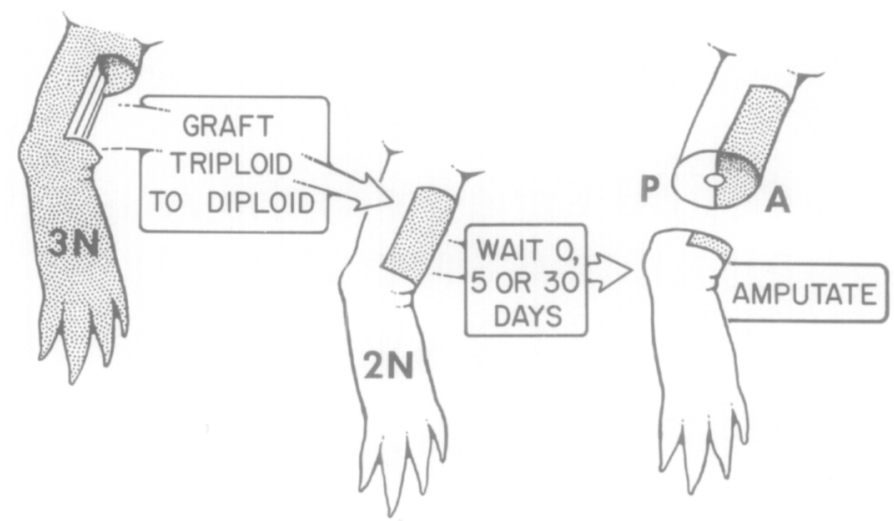

FiG. 1. Experimental design used to create the regenerates analyzed in this study.

intact in the host arm. The limb was wrapped in lens tissue to support the graft and a second operation was performed immediately on the left upper forelimbs. The posterior (extensor) half of the left $2 N$ upper forelimb was replaced by the posterior half of the left $3 N$ upper forelimb. This graft was also secured by lens tissue. Both surgeries resulted in asymmetrical upper forelimbs bearing a full circumferential complement of limb tissues. One half of each limb was $2 N$ and the other half was $3 N$. Following surgery, animals were refrigerated $\left(10^{\circ} \mathrm{C}\right)$ for 2 days to reduce their mobility during the early stages of graft healing. They were then returned to room temperature $\left(18^{\circ} \mathrm{C}\right)$ for the remainder of the experiment.

Animals of the 0-day and 30-day groups underwent a different type of surgery that produced composite limbs identical to those of the 5-day group. These animals were spawned in the laboratory at the University of Arkansas for Medical Sciences and one half of each spawning was made $3 N$ by pressure induction. When embryos had reached stage 34 of development (Schreckenberg and Jacobson, 1975), the right forelimb rudiment of a $3 N$ donor was grafted to the flank of a $2 N$ host (technique of Slack, 1980b). This resulted in a $2 N$ host bearing a $3 N$ limb on its flank from which tissues could be grafted to the normal forelimb at a later larval stage. When larvae bearing flank $3 N$ limbs had reached a minimum length of $105 \mathrm{~mm}$ (range 105$160 \mathrm{~mm}$ ), surgery identical to that described for the 5day group was performed between right $(2 N)$ forelimbs and flank $(3 N)$ forelimbs. Postoperative care of all three groups was as described by Tank (1978b).

Limbs were amputated at three different times after surgery. One group of animals underwent limb amputation immediately after grafting (Day 0), that is, without being permitted to heal. Limbs in a second group were amputated after 5 days of healing (Day 5) and those in a third group were amputated after 30 
days of healing (Day 30). Experimental forelimbs were amputated through the distal end of the graft (immediately proximal to the elbow). Bone and soft tissues were carefully trimmed to create a flat amputation surface.

\section{Histological Analysis}

Limbs were permitted to regenerate to the stage of digital outgrowth (stages according to Tank et al., 1976), when the fourth digital primordium first became visible within the regenerate $\left(28\right.$ days at $\left.18^{\circ} \mathrm{C}\right)$. All forelimbs were drawn with the aid of a camera lucida, and then they were harvested and preserved in Carnoy's fixative. Regenerates were embedded in paraffin and serially sectioned at $10 \mu \mathrm{m}$ in the transverse plane, and the nucleoli were stained by the bismuth technique of Muneoka et al. (1984). Beginning at the distal tip each tenth section was selected for analysis, resulting in a proximal-to-distal spacing of $100 \mu \mathrm{m}$ between samples. Images of selected sections were projected onto bond paper and the external outline, the basal lamina of the epidermis, the outlines of cartilaginous condensations, and the outlines of muscle primordia were traced. The sections were then examined by bright-field or phase microscopy $(\times 400)$ to identify cells displaying the triploid cell marker. The location of each marked cell was then indicated on the tracing as accurately as was possible.

Marked cells were counted in anterior and posterior regions of the regenerates by examining the tracings. The boundary between anterior and posterior was determined as follows: Beginning at the level of the mid-forearm, a line perpendicular to the anteroposterior axis was drawn between the radius and ulna. Proceeding both proximally and distally from this level, a similar line was drawn on each subsequent tracing. Sequentially from fingertips to elbow, the line passed first between digits 2 and 3 , then between the primordia of metacarpals 2 and 3 , then through the middle of the carpal region, and finally between the radius and the ulna, respectively. Marked cells were counted on the anterior or posterior sides of the line. Mesodermal tissues were scored in all groups in this manner. Epidermis was scored only in the 5-day group. Cells were not counted proximal to the elbow.

\section{Cormputer Reconstruction}

The tracings of cross sections were digitized using a Tektronix 4054 computer linked to a Summagraphics digitizing tablet. The outline of each section was recorded first, followed by the outlines of significant internal features (in this study only cartilage was recorded), and finally the positions of triploid cells were entered. Sections in the series were registered to best fit by eye using the camera lucida drawing of the limb which was made at the time of fixation.

The data were recorded on magnetic tape, transferred to a large mainframe computer (Amdahl 5860) at the University of Michigan Computing Center, and plotted by a display package called BIOSURF. This package is a collection of Fortran programs which processes and analyzes data related to the geometry of tissue section boundaries in three-dimensional forms (shapes) which are reconstructed from serial sections. The routines were originally coded by one of us (F.L.B.) and modified by James Kilgore of The University of Michigan for use in the present study.

The display package allows the regenerate to be reconstructed in three dimensions and viewed on a graphics terminal. The regenerate may be rotated around the three major axes, and the display package incorporates hidden line processing. The three-dimensional image may be displayed adjacent to the twodimensional tracings from which it was constructed (Fig. 2), or the two-dimensional tracings may be suppressed. The three components of each limb which were digitized (the outer boundary, the outlines of cartilaginous primordia, and marked cells) may be displayed individually or simultaneously in any combination (Figs. 3, 4). The output of the programs was routed to a CalComp plotter, which generated the twodimensional tracings and three-dimensional drawings.

\section{Histological Controls}

Histological controls were prepared to illustrate the effect of sectioning artifacts on the detection of marked cells and to determine whether background label was present in experimental limbs. The right forelimb of four diploid and four triploid animals was amputated directly above the elbow without previous surgical manipulation. When the resulting regenerates had attained the stage of digital outgrowth (Tank et al., 1976), they were harvested and preserved in Carnoy's fixative. The regenerates were embedded in paraffin, sectioned in the transverse plane, and stained with the nucleolar stain method described above. In each regenerate, 500 nuclei were sampled by light microscopy in each of four sample tissues (epidermis, dermis, muscle, and cartilage). Several histological sections were utilized for this sampling process to ensure that the entire proximodistal extent of the regenerate was examined. Nuclei were designated $1 N$ if one nucleolus was observed, $2 N$ if two nucleoli were observed, and $3 N$ if three nucleoli were present. Nuclei that appeared to contain no nucleoli were not included in the samples. The " $N$ " designation as it is used here is intended to 


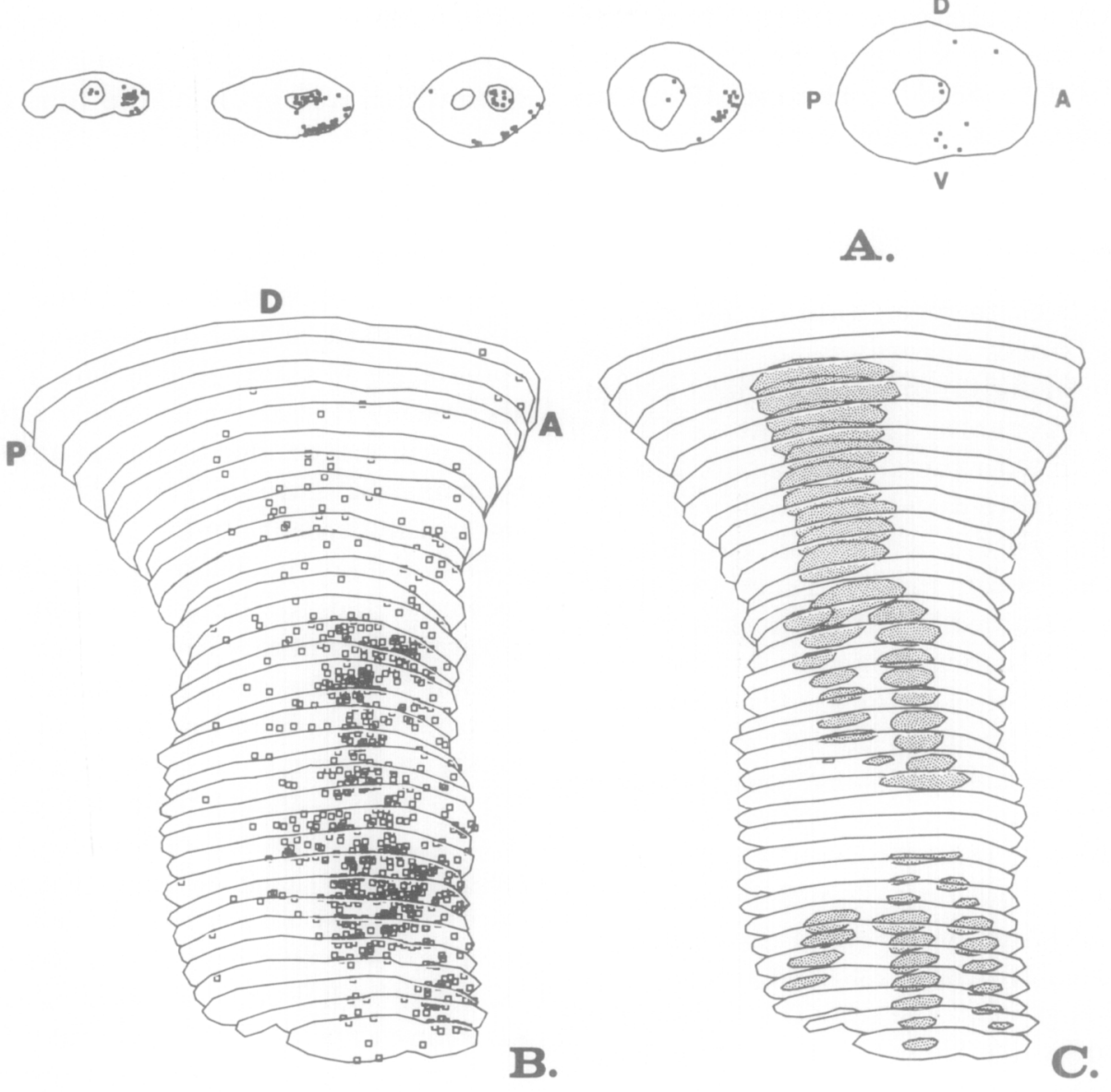

FIG. 2. An example of the display package available by computer imaging. (A) Sample cross-sectional tracings of the limb were selected from different levels in the proximodistal axis (only 5 of the original 29 tracings are shown here). The most distal tracing in this series is at left and the most proximal tracing is at right. The outer line represents the periphery of the cross section; the inner circle or circles represent the contours of cartilaginous primordia of skeletal elements. Each labeled cell appears as a small square. Tracings like these were used to generate the numerical data presented in Table 1. A-anterior; P-posterior; $D$-dorsal; V-ventral. (B) From the series of $2 y$ two-dimensional tracings the computer reconstructs a three-dimensional image of the regenerate and indicates the position of each labeled cell (squares). In this specimen a graft of anterior triploid tissue replaced the anterior side of a diploid limb and most labeled epidermal and mesodermal cells lie within the anterior half of the regenerate. A right regenerate seen in dorsal view. $\mathrm{A}-$ anterior; $\mathrm{P}-$ posterior; $\mathrm{D}-$ dorsal. (C) The positions of cartilaginous primordia within the regenerate are shown in stipple. The primordia of digits 1,2 , and 3 are clearly visible (from right to left, respectively) within the distal tip of the regenerate. The labeled cells have been suppressed in this image.

indicate the visible condition of the nucleolar marker and may not reflect the DNA content of the cells. For instance, cells designated $1 N$ are certainly not haploid $(1 C)$ in DNA content in these somatic tissues.

\section{RESULTS}

\section{Histological Controls}

Histological analysis of $2 N$ regenerates revealed very few $3 N$ cells (Table 1 ). Tissues of mesodermal origin (dermis, muscle, and cartilage) contained less than $1 \%$ of cells that appeared to be marked for triploidy. Only $1.6 \%$ of the cells in diploid epidermis appeared to be marked for triploidy. Regenerates from triploid animals, on the other hand, contained large numbers of $3 N$ cells (Table 1). Epidermis from $3 N$ regenerates contained $61.4 \% 3 N$ cells. Dermis $(49.7 \%)$ and cartilage $(67.7 \%)$ also contained many $3 N$ cells. Muscle from $3 N$ regenerates appeared to contain fewer $3 N$ cells $(22.7 \%$, Table 1$)$. This is probably due to the fact that myonuclei are fusiform with their long dimension in the proximodistal axis, causing more histological sections per nucleus and reducing the chance that three nuclei will be observed in a given section.

The effect of sectioning on the detection of marked cells is illustrated by the results presented in Table 1 . Different types of tissue from the same animal varied widely in the number of $1 N, 2 N$, or $3 N$ cells observed. Also, the high number of $1 N$ cells in diploid muscle and the high numbers of $1 N$ and $2 N$ cells in triploid 

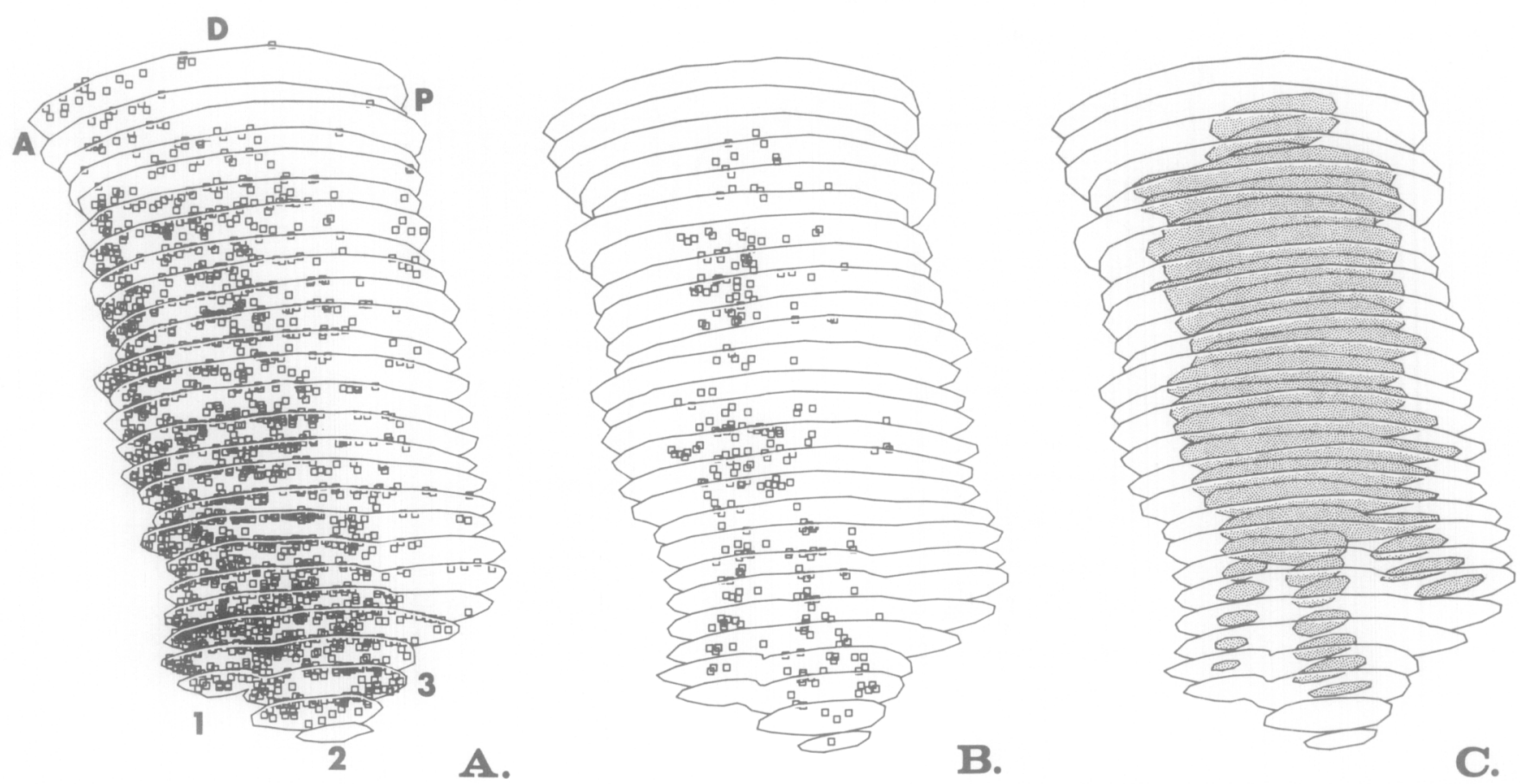

FIG. 3. Computer reconstructions of a regenerate formed on a limb stump composed of triploid anterior tissue and diploid posterior tissue. Each square represents one triploid cell. (A) A left limb seen in dorsal view. The majority of labeled cells is located in the anterior half of this regenerate. Both epidermal and mesodermal cells are indicated in this drawing. Digital primordia 1, 2, and 3 are indicated. Aanterior; P-posterior; D-dorsal. (B) When the labeled epidermal cells are removed from the imagc, it can be seen that labeled mesodermal cells are confined mostly to the anterior half of the regenerate. This is especially noticeable proximally. Farther distally the labeled mesodermal cells are located in digital primordia 1 and 2 and a few labeled cells are present in the interdigital web between digits 2 and 3. Digit 3 contains no labeled cells in its cartilaginous primordium. (C) Cartilaginous primordia are indicated in stipple.

muscle illustrate the loss of marker caused by the plane of histological sectioning.

\section{Experimental}

Light-microscopic observations and counting studies revealed that most $3 N$ cells remained in the region of the regenerate that was directly distal to the marked graft (Table 2). This was true regardless of the length of time grafts were permitted to heal prior to amputation. More specifically, hands that regenerated from limbs with $3 N$ anterior grafts displayed most marked cells in digits 1 and 2 ( 0 day $-76 \%$; 5 days $-79 \% ; 30$ days $-78 \%$ ). Limb stumps bearing $3 N$ posterior grafts regenerated hands with most marked cells in digits 3 and 4 ( 0 day $-77 \%$; 5 days $-71 \%$; 30 days $-78 \%)$. On the average, $23 \%$ of marked anterior cells crossed to the posterior side of the limb, and $24 \%$ of marked posterior cells crossed to the anterior side of the limb (Table 2).

Computer reconstructions of regenerates complemented the numerical data obtained by microscopy. By means of three-dimensional reconstruction it was observed that $3 N$ mesodermal cells from anterior grafts rarely migrated farther posteriorly than digit 3 (Fig.
3B). In fact, the interdigital region between digits 3 and 4 contained marked cells in only 1 limb of 13 studied, although it must be noted that, at the digital outgrowth stage at which limbs were preserved, the fourth digit is underdeveloped. In limbs bearing anterior $3 N$ grafts, the radius contained marked cells in all limbs, but the ulna was labeled very weakly or not at all.

Limb stumps bearing posterior $3 N$ grafts regenerated hands in which only a few $3 N$ cells were observed in cartilage and dermis of digit 2 in 11 of 13 cases. One regenerate contained marked cells in the cartilage of digit 2 but no marked cells were found farther anteriorly. One regenerate contained only one marked cell in the anterior side (Table 2). The ulna was labeled in all 13 experimental limbs, but the radius was labeled in only 7 of 13 regenerates. In general, fewer marked cells were recovered in limbs bearing posterior grafts (Table 2) and marked cells did not appear to spread far anteriorly across the plane of the surgical incision. It must be noted that the posterior side of the hand lags behind the anterior side in rate of development (Grim and Carlson, 1974) so that reduced label in posterior halves could be artifactual. 

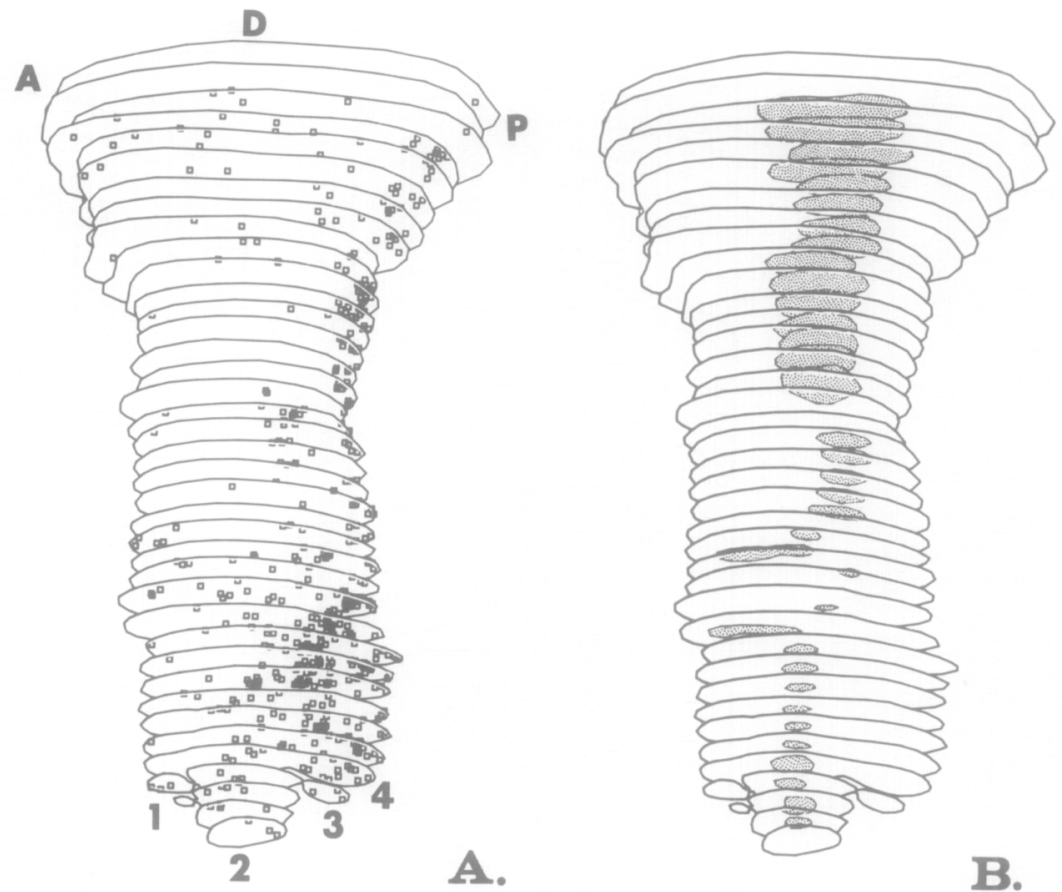

FIG. 4. Computer reconstructions of a regenerate formed on a limb stump composed of anterior diploid tissue and posterior triploid tissue. A left limb seen in dorsal view. Each square represents one triploid cell. Digits 1, 2, 3, and 4 are indicated. A-anterior; P-posterior; D-dorsal. (A) Labeled epidermis and mesoderm are represented on this image. Epidermal cells have migrated around the circumference of this limb and comprise the majority of labeled cells indicated on the anterior surface of the regenerate. Labeled mesodermal cells were observed in digit 2 but not farther anteriorly. The majority of labeled cells remains in the posterior region of the regenerate. (B) Cartilaginous primordia of this regenerate are indicated in stipple.

Marked epidermal cells from anterior grafts were observed at all locations on the posterior surface of the regenerate. They were even observed on the tips of digits 3 and 4 (Fig. 3A). Marked posterior epidermis was observed in all regions of the limb, including the tips of digits 1 and 2 (Fig. 4A). When this result was observed in the initial sample group, analysis of epidermal migration was discontinued in subsequent groups. Therefore, the data in Table 3 were obtained by observing several regenerates in the 5 -day group.

\section{DISCUSSION}

The results presented here indicate that marked mesodermal cells from anterior grafts migrate as far posteriorly as the interdigital region between digits 3 and 4. Marked posterior mesodermal cells migrate as far anteriorly as digit 2 . In contrast, $3 N$ epidermal cells migrated around the circumference of the limb to lie at all locations regardless of whether they were of anterior or posterior origin.

Crossover of mesodermal cells within the regenerate is restrained to the interdigital region between digits 2 and 3 . Our results suggest that posterior mesodermal cells do not migrate as far anteriorly as the first digit. Anterior mesodermal cells do not migrate freely into the fourth digit. Some mixing of mesodermal cells probably occurs in the interdigital region between digits 2 and 3 , since there is no clear line along which marked cells are demarcated from unmarked cells, but the difficulty in recovering $3 N$ label by histology makes it impossible to quantify this. The variable extent of cellular crossover between anterior and posterior limb regions militates against the idea that a compartmental

TABLE 1

Number of Marked Cells Observed in Histological Preparations OF DIPLOID AND 'I'RIPLOID LIMB REGENERATES

\begin{tabular}{lllrr}
\hline & & \multicolumn{3}{c}{ Number (\%) of marked cells } \\
\cline { 4 - 6 } & Total & & & \\
& cells & $1 N$ & $N$ & $3 N$ \\
& 2000 & $370(18.5)$ & $1598(79.9)$ & $32(1.6)$ \\
$2 N$ Epidermis & 2000 & $111(5.5)$ & $663(33.1)$ & $1226(61.4)$ \\
$3 N$ Epidermis & 2000 & $562(28.1)$ & $1426(71.3)$ & $12(0.6)$ \\
$2 N$ Dermis & 2000 & $214(10.7)$ & $793(39.6)$ & $993(49.7)$ \\
$3 N$ Dermis & 2000 & $893(44.7)$ & $1093(54.6)$ & $14(0.7)$ \\
$2 N$ Muscle & 2000 & $508(25.4)$ & $1038(51.9)$ & $454(22.7)$ \\
$3 N$ Muscle & 2000 & $375(18.8)$ & $1611(80.5)$ & $14(0.7)$ \\
$2 N$ Cartilage & 2000 & $107(5.3)$ & $541(27.0)$ & $1352(67.7)$ \\
$3 N$ Cartilage & 2 & & &
\end{tabular}


TABLE 2

Number of Triploid (3N) Mesodermal Celis Observed in the Anterior and Posterior Halves of Regenerated Forelimbs

\begin{tabular}{|c|c|c|c|c|}
\hline \multirow[b]{2}{*}{$\begin{array}{c}\text { Graft } \\
\text { location }^{a}\end{array}$} & \multirow[b]{2}{*}{$\begin{array}{c}\text { Healing } \\
\text { time }^{b}\end{array}$} & \multirow[b]{2}{*}{$\begin{array}{c}\text { Total } 3 N \\
\text { cells }\end{array}$} & \multicolumn{2}{|c|}{$\begin{array}{c}\text { Number }(\%) \\
\text { of cells located in }\end{array}$} \\
\hline & & & $\begin{array}{l}\text { Anterior } \\
\text { half }^{c}\end{array}$ & $\begin{array}{l}\text { Pusterior } \\
\text { half }^{c}\end{array}$ \\
\hline A & 0 & 224 & $183(82)$ & $41(18)$ \\
\hline A & 0 & 422 & $285(68)$ & $137(32)$ \\
\hline A & 0 & 717 & $474(66)$ & $243(34)$ \\
\hline A & 0 & 571 & $443(78)$ & $128(22)$ \\
\hline A & 0 & 642 & $574(89)$ & $68(11)$ \\
\hline A & 0 & 365 & $281(77)$ & $84(23)$ \\
\hline A & 5 & 267 & $246(92)$ & $21(8)$ \\
\hline A & 5 & 318 & $278(87)$ & $40(13)$ \\
\hline A & 5 & 182 & $77(42)$ & $105(58)$ \\
\hline A & 5 & 44 & $42(95)$ & $2(5)$ \\
\hline A & 30 & 344 & $245(71)$ & $99(29)$ \\
\hline A & 30 & 330 & $239(72)$ & $91(28)$ \\
\hline A & 30 & 772 & $645(84)$ & $127(16)$ \\
\hline $\begin{array}{l}\text { Total } \\
\qquad(N=13)\end{array}$ & & 5198 & $4012(77)$ & 1186 \\
\hline$P$ & 0 & 164 & $76(46)$ & $88(54)$ \\
\hline$P$ & 0 & 53 & $16(30)$ & $37(70)$ \\
\hline$P$ & 0 & 93 & $30(32)$ & $63(68)$ \\
\hline $\mathbf{P}$ & 0 & 195 & $33(17)$ & $162(83)$ \\
\hline$P$ & 0 & 137 & $15(11)$ & $122(89$ \\
\hline $\mathrm{P}$ & 0 & 187 & $22(12)$ & $165(88$ \\
\hline$P$ & 5 & 80 & $15(19)$ & $65(81)$ \\
\hline$P$ & 5 & 25 & $1(4)$ & $24(96)$ \\
\hline$P$ & 5 & 170 & $43(25)$ & $127(75)$ \\
\hline $\mathrm{P}$ & 5 & 84 & $44(53)$ & $40(47)$ \\
\hline $\mathrm{P}$ & 30 & 191 & $63(33)$ & $128(67)$ \\
\hline$P$ & 30 & 232 & $46(20)$ & $186(80)$ \\
\hline $\mathrm{P}$ & 30 & 306 & $53(17)$ & $253(83$ \\
\hline $\begin{array}{l}\text { Total } \\
\qquad(N=13)\end{array}$ & & 1917 & $457(24)$ & $1460(76$ \\
\hline
\end{tabular}

${ }^{a}$ Graft location: $\mathbf{A}=$ anterior, $\mathbf{P}=$ posterior.

${ }^{b}$ Healing time: Length of time in days that the graft was permitted to heal prior to amputation. Five-day grafts were made between sibling larvae; 0-day and 30-day grafts were made between flank $(3 N)$ limbs and normal (2N) limbs within the same larva

${ }^{c}$ Limb axes are those described by Tank et al. (1976).

boundary region occurs between digits 2 and 3 that would compare to the strict boundaries observed during wing development (Crick and Lawrence, 1975; GarciaBellido et al., 1973; Garcia-Bellido, 1975). Nevertheless, cells from one side of the limb do not freely intermix with those from the other side to produce a homogeneous mixture in the blastema. This outcome agrees with earlier results obtained when supernumerary limbs were analyzed by $3 N$ labeling techniques (Muneoka and Bryant, 1984a,b) but disagrees with studies in which $3 N$ skin was cross-transplanted within $2 N$ limbs (Rollman-Dinsmore and Bryant, 1984).
Perhaps more significant than the finding that cells do not intermix freely during limb regeneration is the discovery that healing time had no demonstrable effect on cellular behavior in the asymmetrical limb regenerate. Similar percentages of marked cells crossed from anterior to posterior $(24,21$, and $22 \%)$ or from posterior to anterior (23, 29 , and $22 \%$ ) at healing times 0,5 , and 30 days, respectively. This result can be interpreted to mean that the trauma of surgical incision does not affect cellular mobility in the asymmetrical limb regenerate. Of course, conclusions about symmetrical limbs cannot be drawn from these data, but this outcome provides a stimulus to perform a histological study of healing time in symmetrical limbs using $3 N$ grafts into $2 N$ hosts similar to the regeneration study published previously (Tank and Holder, 1978). Results of such a study would be an important test of the healing time hypothesis offered by Bryant et al. (1981).

Grafts between sibling animals (5 days of healing, Table 2) resulted in low numbers of marked cells recovered in the regenerates. Grafts between flank $3 N$ limbs and normal limbs (0-day and 30-day groups, Table 1) produced consistently higher numbers of marked cells recovered from the regenerates. Although no overt signs were noted, the marked cells grafted from siblings may have undergone some graft rejection. The flank limb technique resulted in recovery of more marked cells presumably because there was no graft rejection problem. The total number of cells was reduced in both sides of the limbs in the 5-day group, but the proportion of marked cells in each half remained consistent.

TABLE 3

Number of Triploid ( $3 N$ ) Epidermal Cells Observed on the Antfrior and Posterior Surfaces of Regenerated Forelimbs

\begin{tabular}{lcccc}
\hline & & & \multicolumn{2}{c}{$\begin{array}{c}\text { Number }(\%) \\
\text { of cells located in }\end{array}$} \\
\cline { 3 - 5 } $\begin{array}{c}\text { Graft } \\
\text { location }^{\alpha}\end{array}$ & $\begin{array}{c}\text { Healing } \\
\text { time }^{b}\end{array}$ & $\begin{array}{c}\text { Total } 3 N \\
\text { cells }\end{array}$ & $\begin{array}{c}\text { Anterior } \\
\text { half }^{c}\end{array}$ & $\begin{array}{c}\text { Posterior } \\
\text { half }^{c}\end{array}$ \\
\hline A & 5 & 1107 & $991(89)$ & $116(11)$ \\
A & 5 & 338 & $305(80)$ & $33(10)$ \\
A & 5 & 321 & $309(96)$ & $12(4)$ \\
\multicolumn{1}{c}{ Total } & & 1766 & $1605(91)$ & $161(9)$ \\
P & 5 & 68 & $7(89)$ & $61(11)$ \\
P & 5 & 262 & $59(23)$ & $203(77)$ \\
\multicolumn{1}{c}{ Total } & & 330 & $66(20)$ & $264(80)$ \\
\hline
\end{tabular}

${ }^{a}$ Graft location: $\mathrm{A}=$ anterior, $\mathrm{P}=$ posterior.

${ }^{b}$ Healing time: This limited study of epidermis was performed on limbs that had healed for 5 days prior to amputation.

${ }^{c}$ Limb axes are those described by Tank et al. (1976). 
Epidermal cells do not follow the same pattern of behavior as do mesodermal cells. Epidermal pigmentation patterns have been discussed as evidence for graft survival or contribution of graft mesoderm to supernumerary limbs and as evidence that stump tissues provide intercalary regenerates in the axolotl limb (Stocum, 1980a,b; Tank, 1978a; Wallace and Watson, 1979). We hasten to add that these earlier workers used evidence in addition to pigment markers to support their conclusions. The results of the present study demonstrate that epidermal cell behavior does not necessarily correlate with mesodermal cell behavior during regeneration. This conclusion is substantiated by Lheureux (1983), who has shown that $3 N$ epidermal cells migrate from proximal to distal in regenerating and nonregenerating limbs of Pleurodeles waltl and by Muneoka and Bryant (1984a) in supernumerary limbs formed after blastemal rotation in the axolotl.

The value of the computer reconstruction technique becomes clear when one compares the numerical data to the three-dimensional images. Numerical data indicate that similar percentages of marked epidermal and mesodermal cells cross to the opposite side of each limb analyzed (Tables 2,3 ), but epidermal cells migrated greater distances than did mesodermal cells (Figs. 24). It was by means of computer reconstructions that we were able to determine this difference in cellular behavior exhibited by epidermis and mesoderm.

A few additional points regarding the computer reconstruction methodology deserve mention. First, up to nine internal contours may be recorded and displayed by this technique, although we have selected only two for the present study. Second, the package has many capabilities in addition to the basic display mode used in the present study. For example, if the programs are given information regarding the boundaries of tissue sections and the location of internal contours such as those which represent cartilage in the present study, displays of the outer and inner details can be generated as is shown in the accompanying figures. If the programs are given information regarding the boundaries of the tissue sections and the locations of two populations of cells (e.g., $\left[{ }^{3} \mathrm{H}\right]$ thymidine-labeled cells and unlabeled cells), the programs are capable of (a) smoothing cell densities and cell distribution ratios, (b) computing contours of these smoothed quantities and detecting regions bounded by these contours, and (c) drawing the boundary data and the derived contours in two dimensions and as superimposed reconstructions in three dimensions. Finally, two-dimensional and three-dimensional drawings can be generated in three colors (red, black, blue) to provide additional clarity of detail.
The present study presents new information on cellular behavior in the anteroposterior axis of the regenerating axolotl forelimb. It is hoped that these data and this demonstration of computer reconstruction will stimulate additional research into the cellular basis of pattern formation.

The authors thank Susan Bryant and Nigel Holder for constructive criticism on the experimental design and for words of encouragement. We also express gratitude to Warren Fox for unselfishly donating triploid and diploid sibling axolotls. Jim Crider performed some of the stains and did some of the microscopic analysis. A special thanks to William Brudon for the original illustrations. Janet Hayden provided expert technical assistance and Yvonne Wingfield typed the manuscript. This study was supported by NSF Grants PCM 7920503 and PCM 82-09091 (P.W.T.), PCM 77-04643 (T.G.C.), and PHS Grant DE-05410 (F.L.B.).

\section{REFERENCES}

BRYANT, S. V., and BACA, B. A. (1978). Regenerative ability of doublehalf and half upper arms in the newt, Notophthalmus viridescens. J. Exp. Zool. 204, 307-324.

Bryant, S. V., French, V., and Bryant, P. J. (1981). Distal regeneration and symmetry. Science (Washington, D. C.) 212, 993-1002.

Crick, F. H. C., and LAwrence, P. A. (1975). Compartments and polyclones in insect development. Science (Washingtom, D. C.) 189, 340-347.

DASGUPTA, S. (1962). Induction of triploidy by hydrostatic pressure in the leopard frog, Rana pipiens. J. Exp. Zool 151, 105-121.

French, V., Bryant, P. J., and Bryant, S. V. (1976). Pattern regulation in epimorphic fields. Science (Washington, D. C.) 193, 969-981.

GARCIA-BELLIDO, A. (1975). Genetic control of wing dise development in Drosophila. In "Cell Patterning," Ciba Foundation Symposium No. 29 pp. 161-182. Associated Scientific-Publishers, Amsterdam.

Garcia-Bellido, A., Ripold, P., and Morata, G. (1973). Developmental compartmentization of the wing disk of Drosophila. Nature New Biol. 245, 251-253.

GRIM, M., and CARLSON, B. M. (1974). A comparison of morphogenesis of muscles of the forearm and hand during ontogenesis and regeneration in the axolotl (Ambystoma mexicanum). II. The development of muscular pattern in the embryonic and regenerating limb. Z. Anat. Entwicklungsgesch. 145, 149-167.

HOLDER, N., TANK, P. W., and BRYANT, S. V. (1980). Regeneration of symmetrical forelimbs in the axolotl, Ambystoma mexicanum. Dev. Biol. 74, 302-314.

LHEuReuX, E. (1983). The origin of tissues in the X-irradiated regenerating limb of the newt Pleurodeles waltl. In "Limb Development and Regeneration" (J. F. Fallon and A. I. Caplan, eds.), Part A, pp. 455-465. Alan R. Liss, New York.

MADEN, M. (1977). The regeneration of positional information in the amphibian limb. J. Theor. Biol. 69, 735-753.

Muneoka, K., and Bryant, S. V. (1984a). Cellular contribution to supernumerary limbs in the axolotl, Ambystoma mexicanum. Dev. Biol. 105, 166-178.

Muneoka, K., and Bryant, S. V. (1984b). Cellular contribution to supernumerary limbs resulting from the interaction between developing and regenerating tissues in the axolotl. Dev. Biol. 105, 179-187.

Muneoka, K., Wise, L. D., Fox, W. F., and Bryant, S. V. (1984). 
Improved techniques for use of the triploid cell marker in the axolotl, Ambystoma mexicanum. Dev. Biol. 105, 240-245.

Pescitelli, M. J., Jr., and Stocum, D. L. (1980). The origin of skeletal structures during intercalary regeneration of larval Ambystoma limbs. Dev. Biol. 79, 255-275.

Rollman-Dinsmore, C., and Bryant, S. V. (1984). The distribution of marked dermal cells from small localized implants in limb regeneration. Dev. Biol. 106, 275-281.

SChreckenberG, G. M., and JACoBson, A. G. (1975). Normal stages of development of the axolotl, Ambystoma mexicanum. Dev. Biol. 42, 391-400.

SLACK, J. M. W. (1980a). A serial threshold theory of regeneration. J. Theor. Biol. 82, 105-140.

SLACK, J. M. W. (1980b). Morphogenetic properties of the skin in axolotl limb regeneration. J. Embryol. Exp. Morphol. 58, 265-288.

SLACK, J. M. W. (1983). Positional information in the forelimb of the axolotl: Properties of the posterior skin. J. Embryol. Exp. Morphol. 73, 233-247.

STосUм, D. L. (1975). Regulation after proximal or distal transposition of limb regeneration blastemas and determination of the proximal boundary of the regenerate. Dev. Biol. 45, 112-136.

STocuM, D. L. (1978). Organization of the morphogenetic field in regenerating amphibian limbs. Amer. Zool. 18, 883-896.

STocum, D. L. (1980a). Intercalary regeneration of symmetrical thighs of the axolotl, Ambystoma mexicanum. Dev. Biol. 79, 276295.

Stocum, D. L. (1980b). Autonomous development of reciprocally exchanged regeneration blastemas of normal forelimbs and symmetrical hindlimbs. J. Exp. Zool. 212, 361-371.
TANK, P. W. (1978a). The occurrence of supernumerary limbs following blastemal transplantation in the regenerating forelimb of the axolotl, Ambystoma mexicanum. Dev. Biol. 62, 143-161.

TANk, P. W. (1978b). The failure of double-half forelimbs to undergo distal transformation following amputation in the axolotl, $A$ mbystoma mexicanum. J. Exp. Zool. 204, 325-336.

TANK, P. W. (1981). Pattern formation following $180^{\circ}$ rotation of regeneration blastemas in the axolotl, Ambystoma mexicanum. $J$. Exp. Zool. 217, 377-387.

TANK, P. W. (1982). Pattern regulation during regeneration of embryonically produced symmetrical forelimbs in the axolotl, Ambystoma mexicanum. J. Exp. Zool. 223, 41-50.

TANK, P. W. (1983). Pattern regulation in the anterior half of the embryonically produced symmetrical forelimb of the axolotl, $\mathrm{Am}$ bystoma mexicanum. Amer. .I. Anat. 167, 215-227.

Tank, P. W., Carlson, B. M., and Connelly, T. G. (1976). A staging system for forelimb regeneration in the axolotl, Ambystoma mexicanum. J. Morphol. 150, 117-128.

TANK, P. W., and Holder, N. (1978). The effect of healing time on the proximodistal organization of double-half forelimb regenerates in the axolotl, Ambystoma mexicanum. Dev. Biol. 66, 72-85.

TANk, P. W., and Holder, N. (1981). Pattern regulation in the regenerating limbs of urodele amphibians. Q. Rev. Biol. 56, 113142

Thoms, S. D., and Fallon, J. F. (1980). Pattern regulation and the origin of extra parts following axial misalignments in the urodele limb bud. J. Embryol. Exp. Morphol. 60, 33-55.

WALLACE, H., and WATSON, A. (1979). Duplicated axolotl regenerates. J. Embryol. Exp. Morphol. 49, 243-258. 